\title{
Quality of Family Planning Services in Maternal and Child Health Care Centers in Damanhour City
}

\author{
Samiha Hamdi Sayed ${ }^{1}$, Wafaa Taha Ibrahim Elgzar ${ }^{2} \&$ Heba Abdel-Fatah Ibrahim ${ }^{3}$ \\ ${ }^{1}$ Community Health Nursing, Damanhour University, Egypt \\ ${ }^{2}$ Obstetrics and Gynecologic Nursing, Damanhour University, Egypt \\ ${ }^{3}$ Obstetrics and Woman Health Nursing, Benha University, Egypt \\ Correspondence: Heba Abdel-Fatah Ibrahim, Obstetrics and Woman Health Nursing, Benha University, Egypt.
}

Received: April 25, 2018

Accepted: May 24, 2018

Online Published: June 6, 2018

doi:10.20849/ijsn.v3i2.393

URL: https://doi.org/10.20849/ijsn.v3i2.393

\begin{abstract}
Background: Quality of family planning services is an ever-increasing worldwide issue which is basically deserted in the developing nations. Provision of high quality family planning services that satisfy clients' needs can ensure continued services utilization and increase contraceptive prevalence rate, lowered fertility rate, and improved women and children's health.
\end{abstract}

Aim: this study intended to assess the quality of family planning services in maternal and child health care centers in Damanhour city.

Design: this was a descriptive study that utilized Dounabedian model to assess quality of family planning services structure and process and clients' satisfaction was used as an outcome indicator.

Setting: the three available maternal and child health centers in Damanhour city.

Participants: all health care providers and a convenience sample of 300 non pregnant women who utilized the family planning clinics at the selected maternal and child health centers.

Tools of data collection: three tools were utilized; basic data structured interview schedule for clients and health care providers, structural quality is assessed through facility audit while the process of family planning services provision was measured by using an observational checklist. After the observation of the family planning care process, an exit interview was done with the clients to measure their satisfaction with the provided family planning services.

Results: The study findings revealed that none of the studied family planning clinics had high total quality of care level (structure \& process) where $66.7 \%$ of them had low level of the total quality of care. However, $74.3 \%$ of the studied family planning clients were moderately satisfied with the total quality of care level (structure \& process) in the studied maternal and child health centers. Finally, a significant positive correlation was confirmed between the overall family planning clients' satisfaction level and the total quality of family planning care level; total structure and total process quality of family planning services delivery.

Conclusion and recommendations: it can be concluded that family planning services in maternal and child health centers at Damanhur had low total quality of care level with moderate clients' satisfaction. This shed the light on the urgent need for numerous quality enhancement measures to promote all quality elements in the studied maternal and child health centers. In addition to, emphasizing clients' satisfaction as a high priority output of care.

Keywords: quality, clients' satisfaction, family planning services

\section{Introduction}

The Egyptian population is undergoing a tremendous growth with high fertility rate of 3.47 live births/woman in 2017.Currently, they representing $1.29 \%$ of the worldwide population where they increased from 82,040,944 million in 2010 to $98,023,159$ million in 2017 and expected to reach 102,941,484 by 2020 based on United Nations estimates (United Nations, Department of Economic and Social Affairs, Population Division, 2017). Furthermore, the Egyptian population growth rate $(2.5 \%)$ is more than double compared to that of the world 
population (1.06\%) in 2017 (Central Intelligence Agency [CIA], 2017). This in turn, can have a devastating effect on the country's sustainability. Consequently, the Egyptian government highlighted Reproductive Health $(\mathrm{RH})$ as a national priority (Youssef, Osman, \& Roudi-Fahimi, 2017).

RH is crucial not just for individuals' health and life quality yet in addition for overall community health and progress. Family Planning (FP) is the fundamental component of RH and an indicator of proper RH. It chiefly can succor women in appropriate regulation of pregnancies as regards timing, spacing and limitation. Thus, supports the prevention of high risk, unplanned or mistimed pregnancies which can negatively affect women, fetal, and child health. Such pregnancies can drain mothers' bodies and consequently lead to occurrence of anemia, hemorrhage and abortion which further upsurge the risk of maternal and fetal mortality. They also associated with the reduced rate of health services utilization either during pregnancy or even after labor. Moreover, evidence portrayed that decreased gestational age, birth weight, chance of exclusive breastfeeding, poor kids' mental and psychological health and less close mother to child relationship; are all correlated to unplanned pregnancies (Dibaba, Fantahun, \& Hindin, 2013;Aiken, Dillaway, \& Mevs-Korff, 2015;United Nations Population Fund [UNFPA], 2016).

The importance of RH especially with respect to the accessibility of rights-based and high quality FP services is currently well identified as a curricular motive that direct women for proper service utilization. This is not only essential to improve women's opportunity for having healthy pregnancy and childbirth, but also it contributes to better child health, gender equality, preventing and controlling HIV transmission, enhancing the educational outcomes, reducing poverty and maintenance of sustainable environment (United Nations Population Fund [UNFPA], 2016; Cleland, Bernstein, Ezeh, Faundes, \& Glasier, 2006).

Throughout the world, efforts to ameliorate health of mothers, children and the whole population have been ongoing since the beginning of the nineteenth century. Egypt had participated in the International Conference on Population and Development (ICPD) in 1994.The conference emphasized that people's RH rights for high quality services was the most essential. It also redefined RH services to include FP programs which both provided under the umbrella of primary health care (United Nations Population Information Network [POPIN], 1994; World Health Organization [WHO], 1978).

In the past four decades, -based on United Nations estimates 2016- FP programs have played a great role in elevating the prevalence of contraceptive practice from less than $10.0 \%$ to $64.0 \%$ and reducing fertility in developing countries from 6 to nearly 3 live births per woman. However, the contraceptive utilization rate is showing a lower trend in about half of low income countries (most in Africa) with a raising rates of fertility and unmet FP need (United Nations Population Fund [UNFPA], 2016; United Nations Department of Economic and Social Affairs, Population Division, 2017).

All over the globe the United Nations estimated in 2016 that among married women the unmet FP need was found to be about $12.0 \%$ in those who aged 15 to 49 years. Almost in distinguishable rate (13.0\%) was shown in Egypt; according to Egypt Demographic Health Survey (EDHS 2014).The women with unmet FP need are at higher risk for getting accidental pregnancy with its concomitant negative consequences either undesirable birth or unsafe abortion which carries a massive risk for maternal mortality. The prevalence of unintentional pregnancy in Egypt has been displaying a mounting trend from 14.0\% in 2008 to $16.0 \%$ in 2014. Furthermore, EDHS 2014 results showed that 59.0\% of the Egyptian married women are now utilizing a contraceptive method. The most popular used method was IUD, followed by the pills and injectable. However, about 3 in 10 contraceptive users discontinue their adopted FP method within a year. The adverse effects and FP method failure are the most widely reported causes for method stoppage. In addition, it was found that one of the chief causes for FP methods termination and the escalating rate of unmet FP need is the lack of clients' satisfaction with the services quality. This in turn, reflects the unacceptable quality level of FP services in Egypt which simply unable to match the women with their suitable FP method to achieve their fertility goals (Ministry of Health and Population [Egypt], El-Zanaty and Associates [Egypt], and ICF International. Egypt, 2014; Hutchinson, Agha, \& Do, 2011; Metwally et al, 2015).

Quality of services is a raising integral concern at both the international and national levels especially at RH and FP services, with the main objectives are to safeguard the clients' rights, attraction of more clients and ensure efficiency in services provision. Recently, Institute of Medicine (IOM) demarcated quality of care as the degree to which health care services advance the health outcomes in a way that is consistent with modern qualified knowledge. It also portrays that quality health care should have the following attributes: safe, client-centered, timely, effective, efficient, equitable and accessible to all population (Institute of Medicine, 2010; Institute of Medicine, 2001). 
Specifically, WHO portrayed hat high quality FP services should have the following properties: firstly, equipping the clients with adequate and high quality information about FP to aid them in making their informed choice. This in turn, inspires FP clients to actively participate in making decisions about their FP methods. Secondly, existence of varied choices of inexpensive FP methods to all clients and a favorable system for monitoring and ensuring the continuity of care. Thirdly, the health professionals should have technical competency and interact effectively with all clients using non-judgmental, objective, respectful and supportive attitude. Finally, FP services ought to be combined with other RH services when possible, such as preventing and curing of sexual transmitted infections (World Health Organization [WHO], 2004). This mirrors the mounting trend of providing clients' centered health care which is now considered as a basic aspect of quality health care. Hence, clients' satisfaction with FP services should be considered as a principal and integrated aspect of the service management approaches (World Health Organization, 2007; Agha, Do, 2009).

FP services must possess a quality improvement system that reflects the continuous and systematic actions contributing to measurable progress in the health care process and its targeted outcome. There are multitude of quality monitoring and development frame works such as the holistic Donabedian model which focuses on the three ultimate aspects of health care; namely service structure, process of care provision, and outcome of service delivery(Institute of Medicine, 2010; Institute of Medicine, 2001; Donabedian, Ann, 1980).

The structure of FP services can be considered as is a major influential factor in the health care delivery process. It depicts the features of the setting and the management system for service delivery. It includes physical infrastructure; availability of FP methods, equipment and materials necessary for physical examination and counseling services. In addition to, human resources and the supportive management practices as staff training and continuous supervision (Donabedian, Ann, 1980; Donabedian, 2005).

The process of care clarifies the actual health care delivered through the direct interaction between the client and the practitioner. It responds for two inquiries; what and how services are provided. Efficient and competent FP services is basically depends on the practitioners' performance which entails clinical competence and interpersonal relations. The former is based on level of the practitioners' knowledge and skills for provision of the standardized care. The latter reveals the direct contact between the client and the care provider which is the base for clinical care achievement (Donabedian, Ann, 1980; Donabedian, 2005).

The outcomes of care shape the effectiveness of the delivered health care in achieving its targeted objectives. The coverage rate with FP services and clients' knowledge, behaviors, and clients' satisfaction and its associated continuation rate are among the main indicators of FP services delivery. With the increasing focus on the delivering of client centered health care, clients' satisfaction becomes specifically an indispensable outcome indicator of the quality of care (Donabedian, Ann, 1980; Donabedian, 2005).

Although a plenty of studies works generally on quality of care, there are limited ones which focus on the quality of FP services and clients' satisfaction with such services. Therefore, the aim of the present study was to assess the quality of FP services in maternal and child health care centers at Damanhour city, El-Behira, Egypt. This in turn, will help to identify FP services problems areas which by its role will focus the light on the possible approaches for services improvement and continuity. The Donabedian model was utilized in the current study to assess the quality of the FP services (structure and process) and client satisfaction was used as the outcome variable.

\subsection{Significance of the Study}

Giving that Egypt suffers from higher population growth rate (2.5\%) and higher fertility rate (3.47 live births/ woman); high quality FP services is a necessity for helping the country in ensuring its sustainability. Moreover, with the increasing focus on clients centered health care, client's satisfaction with FP services become an essential outcome indicator of service quality. This in turn, motivates clients for contraceptive utilization and ensuring continuity where higher contraceptives discontinuation rate ( 3 in every 10 women) was found to be a chief obstacle for Egypt improvement. Also, it aids in reducing the escalating trend of unplanned pregnancy in Egypt (United Nations, Department of Economic and Social Affairs, Population Division, 2017; Youssef, Osman, Roudi-Fahimi, 2014).Accordingly, the present study will deliver valuable and factual information which can uphold health care providers, policy makers and managers in improving quality of FP services accordingly.

\subsection{Aim of the Study}

- Assess the quality of family planning services in Maternal and Child Health Care (MCH) centers in Damanhour city, El-Behira, Egypt. 


\subsection{Research Questions}

- What is the level of quality (structure and process) of family planning services in MCH centers at Damanhour city, El-Behira, Egypt?

- What is the level of client satisfaction (outcome) with quality of family planning services in MCH centers at Damanhour city, El-Behira, Egypt?

\subsection{Operational Definitions}

- Quality: in the current study was used to represent the structure and process attributes of FP services.

- Outcome of care: is the effectiveness of the delivered health care and in this study it was measured through clients' satisfaction with FP services.

- Waiting time: is the time that clients have to wait before getting their preferred FP services. In the present study, the acceptable waiting time was equal or less than 30 minutes (Argago, Hajito, Kitilia, 2015 \& Kaoje, Sambo1, Oche, Saad, Raji, Isah, 2015).

\section{Materials and Method}

\subsection{Research Design}

A descriptive research design was utilized to carry out this study.

\subsection{Setting}

The present study was conducted at three FP clinics in the three available Maternal and Child Health Care Centers (MCH) in Damanhour city, affiliated to the ministry of health, El-Behira Governorate; namely El Helal, Shoubra and Abo-Abdualla.

\subsection{Subjects}

- All health care providers working at the three studied FP clinics were enrolled in the study [nurses (10) and physicians (5)].

- 300 married non pregnant women were chosen conveniently from those who were attending the studied FP clinics using equal allocation technique (100 women from each clinic).

The sample size was calculated by using EPI info7 software based on average numbers of contraceptive users in the study centers (3000) and 50\% expected frequency of women's satisfaction with an acceptable error of 5\% and confidence limit of $95 \%$. This resulted in a minimum required sample size of 272 women. The final sample size used was 300 women to compensate for possible non response.

\subsection{Tools of Data Collection}

Three tools were used for data collection.

Tool I: Basic data structured interview schedule:

This tool was developed by the researchers based on a thorough review of relevant literature. It consists of two parts for both clients and health care providers:

- Health care providers' data

- Personal data: age, educational qualification, marital status, and years of experience.

- Training experience about family planning methods, counseling, data and logistics management. In addition to, number of training received and duration of last training.

- Clients' data

- Socio-demographic characteristics: age, education, occupation, residence and income.

- Reproductive history: gravidity, parity, number of living children and intention for subsequent pregnancy.

- Family planning history: the current and previous use of FP methods, duration of use, occurrence of complications from any used FP method, and type of visit (initial/recurrent) and its reason.

Tool II: Quality of family planning services (structure \& process)

It was developed by the researchers based on the selected practice recommendations for contraceptive use developed by World Health Organization (WHO) and FP services quality recommendations designed by Centers for Disease Control and Prevention (CDC) and United States Office of Population Affairs (World Health Organization (WHO), 2004 \& United states Department of Health and Human Services, 2014). It consists of two 
parts:

- $\quad$ Part (A): Structure of FP services assessment sheet

It aimed to measure the structural quality of FP services through facility audit to assure the functional ability of the facility through the availability and adequacy of the required structural items to provide the acceptable standard of care. This tool contains 56 items grouped into six sections namely; infrastructure (12 items), staff number and training (7 items), FP methods (9 items), equipment\& supplies (14 items), Information, education and communication (IEC) materials ( 6 items), and data \& logistics management documents ( 8 items). Each item was scored by the researchers as yes (2) or no (1). The total score of each FP clinic ranged from 56 to 112 then subtracting the minimum from the maximum score to calculate the average score then dividing it by two to categorize the total score into two levels as low structure quality $<84$, and high structure quality $\geq 84$.

\section{- $\quad$ Part (B): Process of FP services observational checklist}

It designed to assess the process quality of FP services provision which represents the professional practices during the actual interaction with each of the studied clients. It consisted of 52 items grouped into 9 sections namely; clients' assessment (7items), physical examination(7items), infection control precautions (6items), laboratory tests (4items), FP counseling (15items), privacy and confidentiality during FP services (2items), respectful behavior (3items), emotional support ( 2 items), data and logistics management (6items). Each item was scored on a likert-scale ranged from 1 to 3 as follows: completely done (3), incompletely done (2), and not done or done incorrectly (1). The total score of each FP clinic ranged between 52 and 156 accordingly the process of quality of care was scored as low process quality $<87$, moderate process quality $87<122$, and high process quality $\geq 122$.

The percent of average total quality of care level is calculated by summing up the structure and process total score then estimating the average calculated total which is then grouped into three levels based on the opinion of expertise in the field of statistics as low total quality of care $<50 \%$, moderate total quality of care $50 \%-75 \%$, and high quality of care $>75 \%$

Tool III: Client's satisfaction structured interview schedule:

This tool was developed by the researchers to assess client's satisfaction with FP clinics' structure and the health care delivery process. It contained two parts:

Part (A): Structure satisfaction scale

It measured the clients' satisfaction with structure of FP services. This scale composed of 21 items grouped into 4 sections namely; infrastructure (11 items), availability of FP methods, equipment and supplies (3 items), center's accessibility ( 4 items), and cost of the provided services ( 3 items). Each item rated on a likert-scale ranged from 1-3: highly satisfied (3), moderately satisfied (2), and unsatisfied (1). The total score for each subject was calculated (ranged from 21 to 63) and grouped into three levels as unsatisfied <35, Moderately satisfied $35<50$, and highly satisfied $\geq 50$.

Part (B): Process satisfaction scale

It measured the clients' satisfaction with the process of FP services provision. It consisted of 31 items grouped into 6 sections namely; the total time spent in the center ( 3 items), registration (1item), physical care (6 items), counseling (10 items), privacy assurance (4 items), and psychological care (7 items). Each statement rated on four point likert-scale ranging from 1-3: highly satisfied (3), moderately satisfied (2), and unsatisfied (1). The total score was calculated (ranged from 31 to 93 ) and categorized into three levels as unsatisfied $<52$, moderately satisfied $52<73$, and highly satisfied $\geq 73$

The overall clients' satisfaction scale consists of 52 statements which was calculated for each subject (ranged from 52to156) and grouped into three levels as follows, unsatisfied $<87$, moderately satisfied $87<122$, and highly satisfied $\geq 122$.

\subsection{Tools Validity and Reliability}

The content validity of all tools was tested through a jury consists of five professors who had expertise in the field and then they were modified accordingly. The internal consistency reliability of the tools was confirmed using Cronbach Alpha Coefficient. The results were statistically acceptable for tool II (part A=0.93), (part $\mathrm{B}=0.88$ ) and tool III (part $\mathrm{A}=0.87$ ), (part $\mathrm{B}=84.0$ ).

\subsection{Pilot Study}

A pilot study was performed on 30 married non pregnant women from the earlier listed MCH centers (not 
included in the study) to ascertain the clarity, applicability, and feasibility of the tools and to identify obstacles that might interfere with the process of data collection. Accordingly, necessary modifications of the tools were done.

\subsection{Ethical Consideration}

For each subject an informed oral consent was obtained after clarifying the aim of the study. Additionally, their anonymity, privacy, and freedom of withdrawal from the study at any time and confidentiality of their data were all emphasized prior to starting of the interview.

\subsection{Field Work}

An official letter from faculty of nursing, Damanhour University was directed to the responsible authorities of the previously mentioned study centers to obtain their permission for conducting the study. All tools (I, II, III) were developed by the researchers after thorough review of relevant literature. The process of receiving FP care was observed for each woman participated in the study. Additionally, exit interview was performed individually for each woman to measure their satisfaction with the provided FP services. During the interview, the researchers had read each item/ question on the data collection sheet and explained its meaning and write down their answers immediately. Each interview lasted for 35-45 minutes. Two days/ week were specified for data collection for about 4 months, started from the March to June 2017. An average of 8-10 interviews were performed/ day. Each center was observed for three hours twice weekly to cover the required items for structure and process quality covered in tool II.

\subsection{Statistical Analysis}

The collected data was revised, categorized, coded, computerized, tabulated and analyzed using version 20 of the Statistical Package of Social Sciences (SPSS). The following statistical measures were used:

- Descriptive statistics: frequency, percent, mean with standard deviation to describe the scale and categorical data.

- Analytical statistics: Spearman rank correlation coefficient (r). P value $\geq 0.5$ was selected as the cut off point for statistical significance.

\section{Results}

The results will be represented into four sections: (I): structure quality, (II): Process quality, (III), outcome of care (clients' satisfaction) and (IV): total quality of FP services and clients' satisfaction.

\section{Section I: Structure quality}


Table 1. Distribution of the health care providers according to their personal data and training experience

\begin{tabular}{|c|c|c|}
\hline Personal data \& training experience & No. & $\%$ \\
\hline \multicolumn{3}{|l|}{ 1. Nurses $(n=10)$} \\
\hline \multicolumn{3}{|l|}{ Age [years] } \\
\hline $30>40$ & 3 & 30.0 \\
\hline $40>50$ & 3 & 30.0 \\
\hline$\geq 50$ & 4 & 40.0 \\
\hline Mean \pm SD (Min-Max) & \multicolumn{2}{|c|}{$44.20 \pm 8.66(30-58)$} \\
\hline \multicolumn{3}{|l|}{ Educational qualification } \\
\hline Diplome & 10 & 100.0 \\
\hline \multicolumn{3}{|l|}{ Marital status } \\
\hline Married & 8 & 80.0 \\
\hline Widowed & 2 & 20.0 \\
\hline \multicolumn{3}{|l|}{ Years of experience } \\
\hline$>5$ & 1 & 10.0 \\
\hline $5>10$ & 3 & 30.0 \\
\hline$\geq 10$ & 6 & 60.0 \\
\hline Mean \pm SD (Min-Max) & \multicolumn{2}{|c|}{$12.70 \pm 8.08(4-30)$} \\
\hline \multicolumn{3}{|c|}{ Receiving of training about FP methods, counseling\& data \& logistics management } \\
\hline Yes & 10 & 100.0 \\
\hline \multicolumn{3}{|l|}{ Number of received training } \\
\hline Once at hiring & 10 & 100.0 \\
\hline \multicolumn{3}{|l|}{ 2. Physicians $(\mathrm{n}=5)$} \\
\hline \multicolumn{3}{|l|}{$\overline{\text { Age (years) }}$} \\
\hline $35>45$ & 2 & 40.0 \\
\hline $45>50$ & 3 & 60.0 \\
\hline Mean \pm SD (Min-Max) & \multicolumn{2}{|c|}{$43.6 \pm 4.9(38-49)$} \\
\hline \multicolumn{3}{|l|}{ Marital status } \\
\hline Married & 5 & 100.0 \\
\hline \multicolumn{3}{|l|}{ Educational qualification } \\
\hline Bachelor's degree (GP) & 4 & 80.0 \\
\hline Specialist & 1 & 20.0 \\
\hline \multicolumn{3}{|l|}{ Years of experience } \\
\hline $5>10$ & 2 & 40.0 \\
\hline $10>15$ & 3 & 60.0 \\
\hline Mean \pm SD (Min-Max) & \multicolumn{2}{|c|}{$10.6 \pm 2.4(8-14)$} \\
\hline \multicolumn{3}{|l|}{ Receiving of training about FP methods\& counseling } \\
\hline Yes & 3 & 60.0 \\
\hline No & 2 & 40.0 \\
\hline Number of received training & $(\mathbf{n}=3)$ & \\
\hline Once at hiring in FP clinics & 3 & 100.0 \\
\hline
\end{tabular}

Table 1 clarifies the distribution of the health care providers according to their personal data and training experience. Forty percent of the nurses working in the studied FP clinics were aged fifty years or more with a mean age of $44.20 \pm 8.66$. All (100.0\%) the studied FP nurses had diplome education and $80.0 \%$ of them were married. The number of nurses' years of experience in FP was found among $60.0 \%$ of them to be ten years or more with a mean of $12.70 \pm 8.08$. Additionally, all (100.0\%) of them had received training about FP methods, counseling and data \& logistics management however the number of training received was only once initial training at hiring in the FP clinic for all (100.0\%) of them. In relation to physicians; $60.0 \%$ of them were aged 45 to less than 50 years with a mean of $43.6 \pm 4.9$, all (100.0\%) of them were married and $80.0 \%$ of them had bachelor's degree (GP) however only $20.0 \%$ where specialist. Sixty percent of physicians had from 10 to less than 15 years of experience with a mean of $10.6 \pm 2.4$. A similar percent $(60.0 \%)$ of them also had received training about FP methods\& counseling; only once at hiring in FP clinics. 


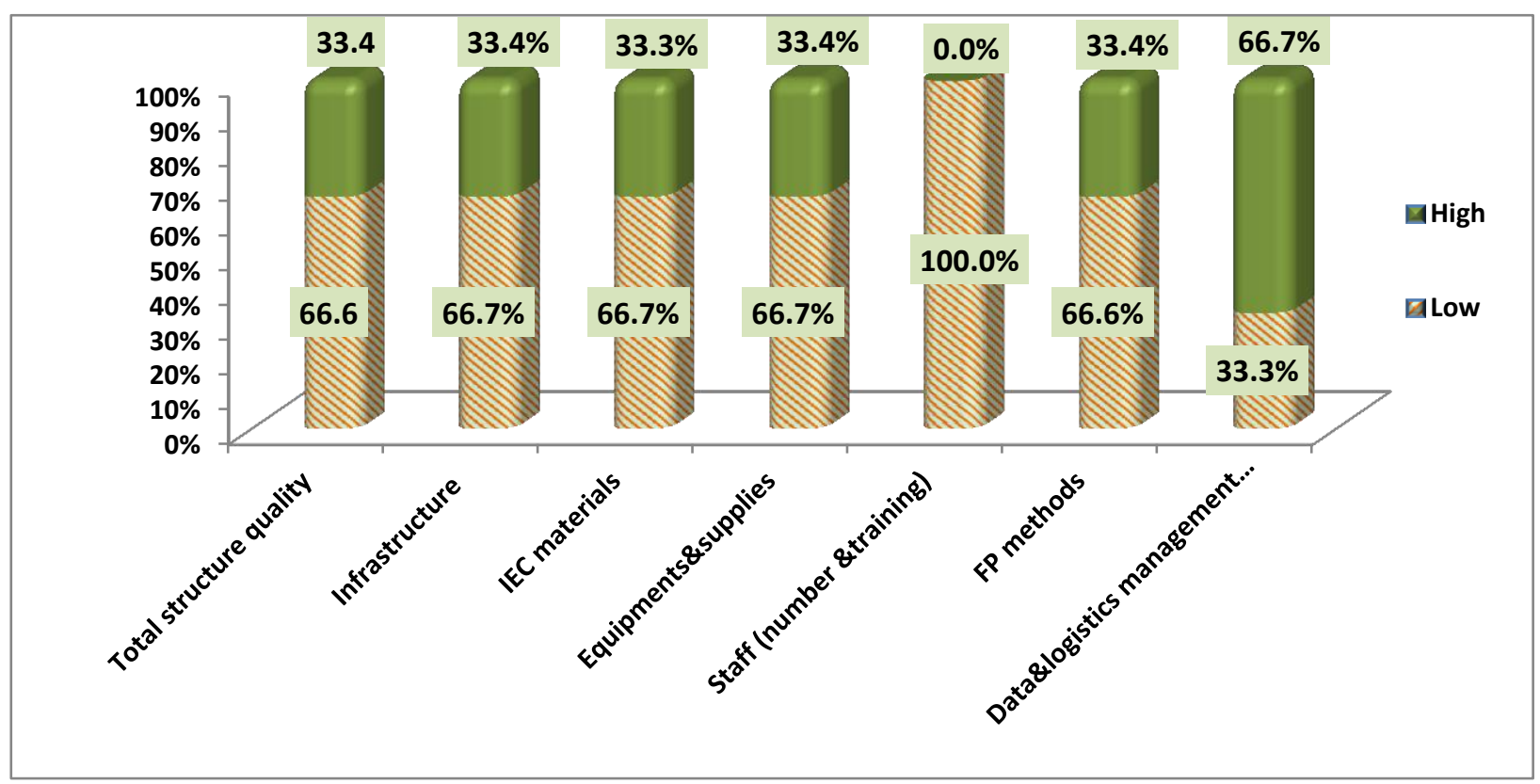

Figure 1. Distribution of the studied FP clinics according to their structure quality level

Figure 1 depicts the distribution of the studied FP clinics according to their structure quality level. It is apparent from the figure that $66.6 \%$ of the studied FP clinics had low total structure quality which was insignificantly varied among the three clinics. Two thirds $(66.7 \%)$ of the studied FP clinics had low quality infrastructure, Information, Education \& Communication (IEC) materials, equipment and supplies, and FP methods. Additionally, all (100.0\%) of the studied FP clinics had low staff number and training however $66.7 \%$ had high quality data and logistics management documents.

Section II: Process of care quality

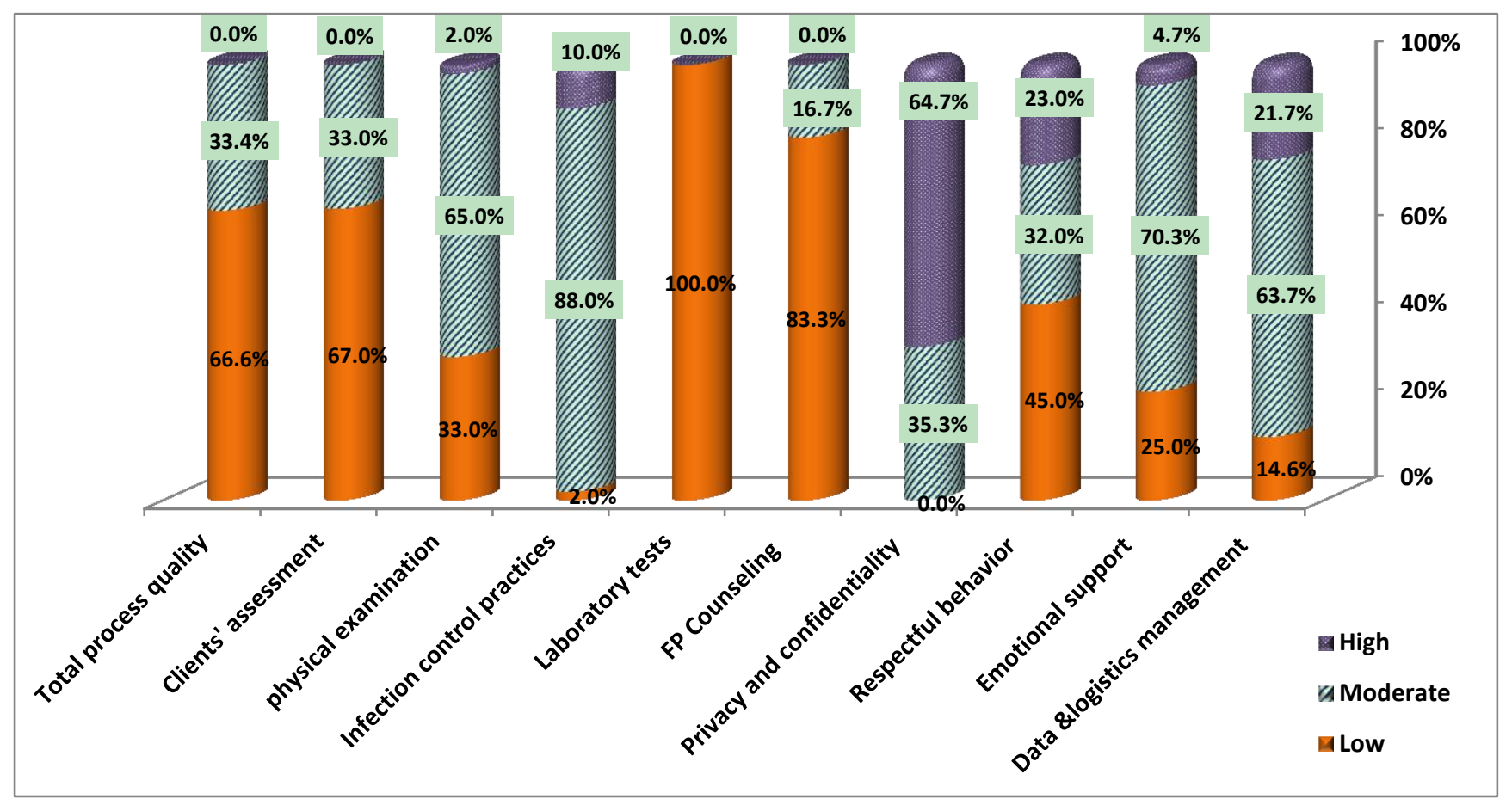

Figure 2. Distribution of the studied FP clinics according to their process of care quality level

Figure 2 explains the distribution of the studied FP clinics according to their process of care quality level. It is 
obvious from the figure that none of the studied FP clinics had high total process of care quality where $66.6 \%$ of them had low total process quality which also was insignificantly varied among the three studied FP clinics. The low quality clients' assessment practices were observed among $67.0 \%$ of the FP clients whereas $65.0 \%$ of them had moderate quality physical examination practices. Also, $88.0 \%$ of them received care with moderate quality infection control practices. All (100.0\%) of the FP clients had low quality laboratory tests (the only done test was the pregnancy test and not for all eligible cases due to temporary unavailability). Additionally, $83.3 \%$ of the FP clients received low quality FP counseling whereas $64.7 \%$ of them had high quality privacy and confidentiality practices. Treating the clients using respectful behavior was found to be of low quality among $45.0 \%$ of the studied FP clients whereas the emotional support experienced during the FP care process was mainly of moderate quality $(70.3 \%)$. Finally, $63.7 \%$ of the studied centers had moderate quality data and logistics management practices.

\section{Section III: Outcome of care (clients' satisfaction)}

Table 2. Distribution of the studied FP clients according to their socio-demographic characteristics \& reproductive history

\begin{tabular}{|c|c|c|}
\hline $\begin{array}{l}\text { Socio-demographic characteristics\& reproductive } \\
\text { history }\end{array}$ & No(300) & $\%$ \\
\hline \multicolumn{3}{|l|}{ Age [years] } \\
\hline$>25$ & 76 & 25.3 \\
\hline $25-35$ & 161 & 53.7 \\
\hline$<35$ & 63 & 21.0 \\
\hline Mean \pm SD & \multicolumn{2}{|c|}{$29.34 \pm 6.06$} \\
\hline \multicolumn{3}{|l|}{ Education } \\
\hline Illiterate or read and write & 76 & 25.3 \\
\hline Basic \&secondary education & 171 & 57.0 \\
\hline Institute or university education & 53 & 17.3 \\
\hline \multicolumn{3}{|l|}{ Occupation } \\
\hline Housewife & 273 & 91.0 \\
\hline Worker & 27 & 9.0 \\
\hline \multicolumn{3}{|l|}{ Residence } \\
\hline Rural & 203 & 67.7 \\
\hline Urban & 97 & 32.3 \\
\hline \multicolumn{3}{|l|}{ Income (women's perspective) } \\
\hline Insufficient \& loan & 188 & 62.7 \\
\hline Sufficient for basic \& emergency needs & 109 & 36.3 \\
\hline Sufficient and saving & 3 & 1.0 \\
\hline \multicolumn{3}{|l|}{ No. of pregnancies } \\
\hline $1-2$ & 141 & 48.0 \\
\hline$\geq 3$ & 159 & 53.0 \\
\hline Mean \pm SD (Min-Max) & \multicolumn{2}{|c|}{$2.82 \pm 1.19(1-7)$} \\
\hline \multicolumn{3}{|l|}{ No. of deliveries } \\
\hline $1-2$ & 160 & 53.3 \\
\hline$\geq 3$ & 140 & 46.7 \\
\hline Mean \pm SD (Min-Max $)$ & \multicolumn{2}{|c|}{$2.39 \pm 0.79(1-6)$} \\
\hline \multicolumn{3}{|l|}{ No. of children } \\
\hline $1-2$ & 167 & 55.7 \\
\hline$\geq 3$ & 133 & 44.3 \\
\hline Mean \pm SD $($ Min-Max $)$ & \multicolumn{2}{|c|}{$2.38 \pm .79(1-6)$} \\
\hline \multicolumn{3}{|l|}{ Plan for next pregnancy } \\
\hline Yes & 69 & 23.0 \\
\hline No & 231 & 77.0 \\
\hline
\end{tabular}

Table 2 illustrates distribution of the studied FP clients according to their socio-demographic characteristics and reproductive history. More than half $(53.7 \%)$ of the studied FP clients aged from 25 to less than 35 years with a 
mean age of $29.34 \pm 6.06 .57 .0 \%$ of the studied FP clients had completed basic and secondary education, $91.0 \%$ of them were housewives and $67.7 \%$ of them were rural residents. Finally, $62.7 \%$ of the studied FP clients had insufficient income \& loan. A nearly similar percent $(53.0 \%, 53.3 \%)$ of the studied FP clients had either three or more pregnancies or deliveries with a mean number of deliveries of $2.39 \pm 0.79$ and a mean number of pregnancies of $2.82 \pm 1.19$. Having one or two children were found among $55.7 \%$ of the studied FP clients with a mean number of $2.38 \pm 0.79$. Finally, $77.0 \%$ of the studied FP clients hadn't a plan for next pregnancy.

Table 3. Distribution of the studied FP clients according to their FP history

\begin{tabular}{|c|c|c|}
\hline $\begin{array}{l}\text { Family planning history } \\
\end{array}$ & No. (300) & $\%$ \\
\hline \multicolumn{3}{|l|}{ Utilized FP method (currently/previously)\# } \\
\hline IUDs & 246 & 82.0 \\
\hline Minipills & 80 & 26.7 \\
\hline Injection & 72 & 24.0 \\
\hline Combined pills & 66 & 22.0 \\
\hline Capsules & 20 & 6.7 \\
\hline Male condom & 4 & 1.3 \\
\hline \multicolumn{3}{|l|}{ Duration of FP method use (years) } \\
\hline$>3$ & 171 & 57.0 \\
\hline $3>6$ & 56 & 18.7 \\
\hline$\geq 6$ & 73 & 24.3 \\
\hline \multicolumn{3}{|l|}{ Occurrence of complications from FP methods } \\
\hline Yes & 189 & 63.0 \\
\hline No & 111 & 37.0 \\
\hline Complications associated with FP methods \# & $(n=189)$ & \\
\hline Bleeding & 66 & 22.0 \\
\hline Unintended pregnancy & 37 & 12.3 \\
\hline Vaginal infection & 34 & 11.3 \\
\hline Menstrual irregularities & 28 & 9.3 \\
\hline Weight gain & 25 & 8.3 \\
\hline Displaced IUDs & 17 & 5.7 \\
\hline Severe backache & 14 & 4.6 \\
\hline \multicolumn{3}{|l|}{ Visit type } \\
\hline Initial & 53 & 17.7 \\
\hline Recurrent & 247 & 82.3 \\
\hline \multicolumn{3}{|l|}{ Reasons for current visit to FP clinic } \\
\hline Follow up & 168 & 56.0 \\
\hline Initiate new FP method & 94 & 31.3 \\
\hline Change the current method & 22 & 7.3 \\
\hline Removal of the current method & 8 & 2.7 \\
\hline Resupply of FP method (pills, injection....) & 8 & 2.7 \\
\hline \multicolumn{3}{|l|}{ Reasons for selecting the FP clinic } \\
\hline Accessibility & 116 & 38.7 \\
\hline Good reputation & 87 & 29.0 \\
\hline Cost effectiveness & 44 & 14.7 \\
\hline Recommended by relatives & 27 & 9.0 \\
\hline Habituation & 12 & 4.0 \\
\hline Availability of most FP methods (capsules) & 10 & 3.3 \\
\hline Availability of ultrasound device & 4 & 1.3 \\
\hline
\end{tabular}

\#Total is not mutually exclusive

Table 3 displays distribution of the studied FP clients according to their family planning history. The majority $(82.0 \%)$ of the studied FP clients utilized IUDs and around one quarter $(26.0 \%, 24.0 \%, 22.0 \%)$ of them utilized either minipills, injection or combined pills, respectively.57.0 \% of the studied FP clients utilized FP method for less than 3 years and $63.0 \%$ of them had complications from their utilized FP method. The most common 
complications encountered among the studied FP clients were bleeding (22.0\%), unintended pregnancy (12.3\%), and vaginal infection $(11.3 \%)$. The majority $(82.0 \%)$ of the studied FP clients were recurrent users to the FP clinics. As regards the reason for the current visit, 56.0\% of the studied FP clients attended the FP clinics for follow up and 31.3\% of them for using a new FP method. Additionally, attendance of the FP clinics for changing or removing of the utilized FP method or resupply of their periodic FP method as pills or injection were found among $7.3 \%, 2.7 \%, 2.7$ of them, respectively. The most common reported reasons for selecting the FP clinics among the studied FP clients were accessibility (38.7\%), good reputation (29.0\%), and cost effectiveness $(14.7 \%)$.

Table 4. Distribution of the studied FP clients according to their satisfaction with quality of family planning services

\begin{tabular}{|c|c|c|c|c|c|c|}
\hline \multirow[t]{2}{*}{ Satisfaction with FP items } & \multicolumn{2}{|c|}{ Unsatisfied } & \multicolumn{2}{|c|}{$\begin{array}{l}\text { Moderately } \\
\text { satisfied }\end{array}$} & \multicolumn{2}{|c|}{$\begin{array}{l}\text { Highly } \\
\text { satisfied }\end{array}$} \\
\hline & No. & $\%$ & No. & $\%$ & No. & $\%$ \\
\hline \multicolumn{7}{|l|}{ Structure } \\
\hline a. Infrastructure & 25 & 8.3 & 215 & 71.7 & 60 & 20.0 \\
\hline $\begin{array}{l}\text { b. Availability of FP methods, equipment and } \\
\text { supplies }\end{array}$ & 9 & 3.0 & 187 & 62.3 & 104 & 34.7 \\
\hline c. Accessibility & 22 & 7.3 & 185 & 61.7 & 93 & 31.0 \\
\hline d. Cost & 13 & 4.3 & 98 & 32.7 & 189 & 63.0 \\
\hline Total structure & 12 & 4.0 & 221 & $\mathbf{7 3 . 7}$ & 67 & 22.3 \\
\hline \multicolumn{7}{|l|}{ Process of care } \\
\hline Total time (waiting, counseling, examination) & 40 & 13.3 & 63 & 21.0 & 197 & 65.7 \\
\hline Registration procedures & 25 & 8.3 & 189 & 63.0 & 86 & 28.7 \\
\hline Physical care & 146 & 48.7 & 140 & 46.7 & 14 & 4.7 \\
\hline Privacy and confidentiality & 41 & 13.7 & 205 & 68.3 & 54 & 18.0 \\
\hline Counseling & 113 & 37.7 & 156 & 52.0 & 31 & 10.3 \\
\hline Psychological care & 69 & 23.0 & 192 & 64.0 & 39 & 13.0 \\
\hline Total process of care & 73 & 24.4 & 193 & 64.3 & 34 & 11.3 \\
\hline General satisfaction & \multicolumn{2}{|c|}{$\underline{\underline{Y e s}}$} & \multicolumn{3}{|c|}{$\underline{\text { No }}$} & \\
\hline & No. & $\%$ & No. & & $\%$ & \\
\hline $\begin{array}{l}\text { Follow up their used method in the same } \\
\text { MCH center }\end{array}$ & 261 & 87.0 & 39 & & 13.0 & \\
\hline $\begin{array}{l}\text { Come back to the same } \mathrm{MCH} \text { center if they } \\
\text { need any FP services }\end{array}$ & 244 & 81.3 & 56 & & 18.7 & \\
\hline Recommend the center for their relatives & 244 & 81.3 & 56 & & 18.7 & \\
\hline
\end{tabular}

Table 4 portrays the distribution of the studied FP clients according to their satisfaction level with quality of family planning services. In relation to the structure of the studied FP clinics, $73.7 \%$ and $22.3 \%$ of the studied FP clients were either moderately or highly satisfied with the total structure of the studied FP clinics, respectively. $71.7 \%$ and $20.0 \%$ of the studied FP clients were either moderately or highly satisfied with the studied centers' infrastructure. In addition, $62.3 \%$ and $34.7 \%$ of them were also either moderately or highly satisfied with availability of equipment, supplies and FP methods. Most of the studied FP clients were either moderately $(61.7 \% \& 32.7 \%)$ or highly $(31.0 \% \& 63.0 \%)$ satisfied with accessibility and cost of the FP services, respectively.

Regarding the process of care, $64.3 \%$ of the studied FP clients were moderately satisfied whereas $24.4 \%$ were unsatisfied with the total process of care in the studied FP clinics. The total time spent in the FP clinics was found to highly satisfy $65.7 \%$ of the studied FP clients whereas $63.0 \%$ of them were moderately satisfied with the registration procedures. However, $48.7 \%$ of them were unsatisfied with the physical care process, respectively. Additionally, the highest percent $(68.3 \%, 18.0 \%)$ of them were either moderately or highly satisfied with maintenance of their privacy and confidentiality, respectively. Similarly, the highest percent $(37.7 \%, 52.0 \%)$ of the studied FP clients were unsatisfied or moderately satisfied with the counseling process, respectively. Finally, 23.0\% and $64.0 \%$ of them were either unsatisfied or moderately satisfied with the psychological aspects of care, respectively. As regards the general satisfaction, the majority (87.0\%) of the studied FP clients reported that they will follow up their used FP method in the same FP clinic. In addition, a similar percent $(81.3 \%)$ of 
them also reported that they will come back to the same FP clinics if they need any FP services and recommended it to their relatives.

\section{Section IV: Total quality of care and clients' satisfaction level}

Figure 3. Total quality of care and clients' satisfaction level in the three studied FP clinics

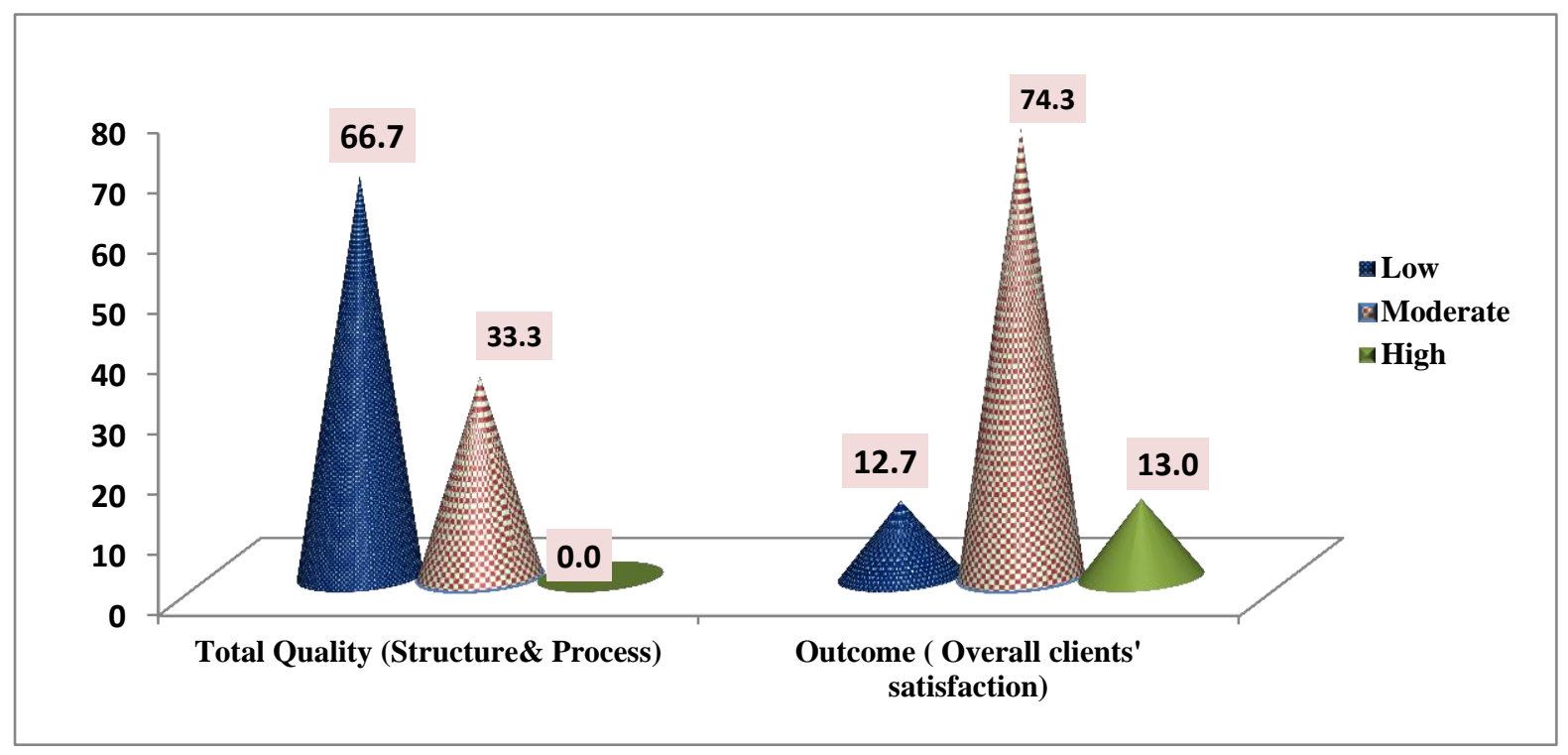

Figure 3 ilustrates the quality of care and clients' satisfaction level in the three studied FP clinics. It is depicted from the figure that non of the studeid FP clinics had high total quality of care level (structure \& process) and $66.7 \%$ of them had low total quality of care level. However, $74.3 \%$ of the studied FP clients had moderate overall satisfaction level with quality of FP care in the studied FP clinics.

Table 5. Correlation between quality of care level (structure \&process) among the three studied FP clinics and their clients' overall satisfaction level

\begin{tabular}{lcc}
\hline Quality of care & \multicolumn{2}{c}{ Quality Satisfaction Level (Outcome) } \\
& $r$ & $\boldsymbol{P}$ \\
\hline Structure & 0.567 & $0.035^{*}$ \\
Process & 0.867 & $0.047^{*}$ \\
Total quality of care & 0.017 & $0.03^{*}$ \\
\hline
\end{tabular}

*Significant at $\mathrm{P} \leq 0.05$; r: Spearman Rank Correlation coefficient

Table (VI) shows the correlation between quality of care (structure \&process) level among the three FP clinics and their clients' overall quality satisfaction level. It is noticed from the table that there is statistically significant positive correlation between clients' overall satisfaction level(outcome) and total quality of care level (structure \& process) $(\mathrm{r}=0.017, \mathrm{p}=0.03)$, structure quality $(\mathrm{r}=0.567, \mathrm{p}=0.035)$, and process quality $(\mathrm{r}=0.867$, $\mathrm{p}=0.047$ ).

\section{Discussion}

With the growing approach of the client-centered health care, there is a rising focus on providing high quality FP services which is of utmost importance to improve women and child health and clients' satisfaction with FP services which in turn fosters contraceptive prevalence and continuation of FP services utilization.

The study findings revealed that none of the studied FP clinics had high total quality of care level (structure \& process) where two thirds of them had low quality and the other third had moderate quality of care level. It was further insignificantly varied among the studied FP clinics. Similarly, Tafese et al (2013) carry out a study in Ethiopia to assess the quality of FP services in primary health centers. The study revealed that most of the studied FP clinics had low total quality of care level. Conversely, Nasr and Hassan (2016) showed that the 
majority of the studied FP clinics had satisfactory total quality of care level either in structure or process components of FP services. They studied the association between quality of FP services and client's satisfaction level in MCH centers in Port Said city. Such discrepancy between the current study and the later one may be attributed to the sample size where it was higher in the aforementioned study than the present one which can provide a chance for great variation in the quality of care level. In addition to, the higher infrastructure quality which was found in the former study than the current one as it is of utmost importance for provision of high quality FP services.

Without the availability of acceptable facility structure index, achieving high services quality of care level is fictitious (Tessema, 2017 \& Wakjira, 2017). The current study showed that two thirds of the studied FP clinics had low total structure quality especially with respect to infrastructure, Information, Education and Communication (IEC) materials, equipment \& supplies, and FP methods. Additionally, all of the studied FP clinics had low staff number and training however $66.7 \%$ of them had high quality data and logistics management documents. This was insignificantly varied among the studied FP clinics.

Consistent findings were portrayed by four studies. First, Tessema et al (2017) conducted a study in Ethiopia to examine the determinants of quality of care in FP services. They portrayed that the studied facilities had unsatisfactory structure quality where nearly half of them didn't have performance guidelines or protocols and lacked the simple care instruments as weight and blood pressure apparatus. Second, Wakjira (2016) conducted another study in Ethiopia to assess client satisfaction with FP services utilization and explored that the studied FP clinics lacked the availability of needed FP methods where the most dominant method were hormonal ones. Third, Assaf et al (2015) examined the quality of care in FP services in Senegal. They found that the studied public health facilities had lack of electricity, communication materials, emergency transportation, computer \& internet connection, and equipment. Fourth, the previously mentioned study of Tafese et al (2013) depict that the majority of the studied FP clinics had unsatisfactory structure quality with lack of trained staff, IEC materials, equipment and supplies and FP practice guidelines. They further added that FP clinics had high quality system for data and logistics management.

Conversely, two previously mentioned studies had shown inconsistent findings. First, Nasr and Hassan (2016) point out that the most of the studied FP clinics had satisfactory total structure quality. Second, Assaf et al (2015) revealed that most of the studied FP clinics had the basic infrastructure needed for provision of quality FP services especially with respect to the availability of water supply, cleanliness, separate room for examination, at least one skilled staff, and wide range of FP methods. Additionally, a third study in urban Kenya by Tumlinson (2014) was carried out to assess the quality of FP services. It clarified that the studied FP clinics had acceptable total structure quality level especially in relation to availability of FP methods, infrastructure, performance guidelines and proper quality assurance methods as periodic supervision and training of staff.

The FP care delivery process is predominantly based on the providers' technical competency and interpersonal skills which are significant determinants to clients' satisfaction and continuity of care (Tafese, Woldie, \& Megerssa, 2013; Assaf, Wang, 2015). The present study results proved that none of the studied FP clinics had high total process of care quality where $66.6 \%$ of them had low total process quality mainly with respect to; laboratory tests, FP counseling, clients' assessment, physical examination, respectful behavior, and emotional support, respectively. Conversely, $64.7 \%$ of them had high quality privacy and confidentiality practices and moderate $(63.7 \%)$ to high $(21.7 \%)$ data and logistics management practices.

Concurred findings were illustrated by three earlier listed studies. First, Wakjira (2016) explored that the studied FP clinics had poor process quality mainly with respect to counseling and physical care. The study documented that hormonal FP methods were given to clients without assessment of vital signs and physical examination which is congruent with the current study findings. Second, Assaf et al (2015) explored that all the studied FP clinics had low process attributes quality especially physical examination and counseling which was mainly provided to new client more than returning ones. Third, Tasefe et al (2013) reported that all the studied FP clinics had unsatisfactory total process quality especially in terms of the technical competency of the providers. They clarified that the studied FP staff had poor performance not only in counseling and duration of consultation but also in physical examination and assessment of clients' data. In addition to, a fourth, study by De Silva and Fonseka (2008) who examined the quality of care in government FP clinics in Sri Lanka. They showed that the provider-client interpersonal relation had unsatisfactory quality where providers treat clients using irrespective attitude and didn't provide sufficient time to talk with clients about their inquiries and needs.

Unsatisfactory quality of laboratory services was proved by Simbar et al (2004) who assessed the quality of FP services in urban health centers in Iran. They found that the studied facilities had irrational system for 
conducting lab tests with no performance of follow up test. This is congruent with the current study results which showed that in all the studied FP clinics, the only performed lab test was the pregnancy test which wasn't always available to be done for all cases. This put a burden on clients to pay for such unavailable services as they were referred to other facilities or private centers to do the laboratory tests with extra fees. In addition, they may use FP methods without performing the needed investigations which may put their health at serious risks.

Despite the availability of limited contradicting results, all of which unanimously agreed with the present study findings with respect to, lack of utilization of FP guidelines and educational materials during service provision and comprehensiveness of counseling. First, Nasr and Hassan (2016) showed that the majority of the studied FP clinics had satisfactory total FP process quality especially regarding counseling and infection control practices. Second, Tessema et al (2017) elaborated that clients' privacy either visual or auditory was not maintained for the majority of the studied clients. Third, Simbar (2004) explored that the studied facilities had high total process quality of FP services especially with regard to clients' assessment, physical examination, communication, respecting and counseling. However, method specific FP counseling including the technical guidance for using was found to be of moderate quality. These findings reflect that despite the variability in findings between the current study and other study findings, there is no absolute high quality of care level. Each study had discovered numerous strength and weak points in FP services delivery process. This may be elucidated by the variance among the health systems throughout countries and to what extent they focused on the primary health care centers either by provision of adequate infrastructure or technically competent staff with availability of satisfactory quality control and improvement procedures.

Clients' satisfaction is a basic and complementary aspect of the service management strategies which draws the road for service improvement measures and can directly reflect the health services utilization rates (Tumlinson, 2014; Agwanda, Khasakhala, \& Kimani, 2009). The present study results inferred that $74.3 \%$ of the studied subjects were moderately satisfied with the total quality of FP services (structure and process) whereas nearly equal percent $(13.0 \%, 12.7 \%)$ of them were either highly satisfied or unsatisfied with total quality of FP services. This figure is in line with four studies. First, Argago et al (2015) found that $75.3 \%$ of the studied clients were moderately satisfied with the overall quality of FP services. They studied clients' satisfaction with quality of FP services in South Ethiopia public health facilities. Second, Kaoje et al (2015) illustrated that $84.9 \%$ of the respondents were moderately satisfied with the FP services whereas $15.1 \%$ were unsatisfied. They assessed the predictors of women satisfaction with FP services quality in Nigeria. Third, Tumlinson (2014) portrayed that 90.0\% of the studied subjects were satisfied with the overall quality of FP services. Fourth, Agwanda et al (2009) assessed the quality of FP services in Kenya. They displayed that $91.0 \%$ of the studied client were moderately satisfied with the total quality of care in FP services.

A contrary figure was postulated by numerous studies. First, Assaf et al (2015) examined the quality of care in FP services at health facilities in Senegal. They explored that $84.0 \%$ of the studied clients stated that they were greatly satisfied with total quality of FP services. Second, earlier listed study by Nasr and Hassan (2016) reported that the majority of the clients were highly satisfied with FP services with a mean percentage of $95.4 \%$. This discrepancy may be attributed to the dissimilarity in the cultural background among clients which can play a decisive role in their perception of what is good or bad. In addition to, the lower level of clients' knowledge and awareness with the acceptable standard of care in the FP services. Furthermore, it seems to be logic as in these contradicted studies the examined facilities had good total quality of care level however in the current study none of the studied FP clinics had high quality of care level.

Service structure can be considered as a major influential factor in the clients' satisfaction with services provision. ${ }^{(29,33)}$. The present study illustrated that the majority $(73.3 \%, 22.3 \%)$ of the studied FP clients were either moderately or highly satisfied with the total structure quality of FP services especially; cost, availability of FP methods, equipment and supplies, facility accessibility and infrastructure, respectively. Additionally, the most common reported reasons for selecting the FP clinics among the studied clients were accessibility (38.0\%), good reputation $(29.0 \%)$, and lower cost $(14.7 \%)$.

Concurred findings were reported by three recent studies. First, a previously mentioned study by Nasr and Hassan (2016) explored that the great majority of the respondents were satisfied with structure quality items specifically accessibility, availability and cost of FP methods. Second, earlier listed study by Argago et al (2015) proved that the clients were satisfied with structure quality of FP services particularly the facility cleanliness and accessibility in terms of convenient working hours. Third, Hutchinson et al (2011) carried out comparative study of client satisfaction and FP services quality in governmental and private facilities in Kenya, Ghana and Tanzania. They detected that most on the studied women were satisfied mainly with FP methods availability especially at the public facilities. 
A contradicting figure was portrayed by three studies. First Rehman et al (2015) assessed client satisfaction regarding FP services in a reproductive center in Pakistan. They found that majority of the clients were unsatisfied with FP methods availability, health facility accessibility with respect to working hours. Second, a former mentioned study by Agwanda et al (2009) indicated also that $25.0 \%$ of the studied subjects were unsatisfied with the availability of FP methods and treatment medications. Third, dissatisfaction with the service infrastructure especially toilets facilities, cleanliness, and waiting area was explored by the majority of the clients in a previously mentioned study by De Silva and Fonseka (2008). This discrepancy may be attributed to the higher clients' expectation and awareness with FP services structure quality standard which could be a reason for facility shortcoming in fulfillment of clients' satisfaction.

Clients' satisfaction with process of FP care mainly shapes the actual experience of the clients with the services' providers. The present study outlined that $64.3 \%$ of the FP clients were moderately satisfied with the total process of care whereas $24.4 \%$ of them were unsatisfied with one or more quality aspect of the received FP services; mainly physical care (48.7\%), counseling (37.7\%), psychological care (23.0\%).

Concurred findings were shown by five previously mentioned studies. First, Tessema et al (2017) explored that more than two fifths $(41.5 \%)$ of the clients were less satisfied with process quality of FP services particularly; physical examination, history taking and contraceptive counseling. Second, Wakjira (2017) showed that more than half $(55.0 \%)$ of the clients were dissatisfied with the total process of care especially information given during counseling and physical examination. Third, Argago et al (2015) found that $24.7 \%$ of the clients were unsatisfied with the quality of the delivered FP services particularly the staff technical competence abilities. Fourth, Rehman et al (2015) showed that the respondents were unsatisfied with providers' competency (90.2\%) and their attitude and behavior (89.0\%) mainly in relation to the psychological part of the received care. This may be related to scarcity of the health care professionals and the periodic supervision and training where in the present study almost all providers received training only once at hiring. Additionally, all nurses working in FP clinics had diplome education and most of physicians had bachelor's degree or worked as general practitioner.

Contradictory findings were shown by four studies. First and second, Mohamed S et al (2017) and a previously mentioned study by Nasr and Hassan (2016) found that the majority of the women were highly satisfied with the total quality of the process of FP services provision. The former described the Egyptian women's satisfaction with FP services in MCH centers. Third, Tumlinson (2014) explored that the majority of respondents were satisfied with the overall process quality particularly FP counseling. Fourth, De Silva and Fonseka (2008) explored that the majority (97.5\%) of respondents were satisfied with providers' competency in care provision. This may be attributed to lack of clients' awareness about the technical aspect of care which requires higher level of knowledge about professional FP procedures and performance guidelines. In addition to, the employed quality control and improvement measures in those contradictory studies such as regular in service training and continuous supervision of the staff which were deficient in the existing study.

Otherwise, the present study illustrated that the majority $(68.3 \%, 18.0 \%)$ of FP clients had either moderate or high satisfaction level with privacy\& confidentiality issues, respectively. This is in line with three former listed studies namely; Tessema et al (2017), Tumlinson (2014) and Hutchinson et al (2011) which explored a statistically significant relationship between women's satisfaction level and privacy matters during FP services delivery where the most of women were satisfied with both privacy issues and confidentiality of their information. A contrary figure was shown with two previously mentioned studies. First, Rehman et al (2015) observed that the highest percent of the respondents were either dissatisfied or highly dissatisfied with maintenance of their privacy $(68.1 \%, 11.0 \%$ respectively) during FP services provision. Second, Agwanda et al (2009) explored that most women were unsatisfied with protection of their privacy during the care process. This may be attributed to the Egyptian culture and the widespread Islamic religion which focuses on promotion and maintenance of modesty and privacy. Thus, all staff should be oriented with such issues to provide culturally optimal care which in turn improve clients' satisfaction.

Moreover, The current study portrayed that despite the longer time spent by the clients in the FP clinics (waiting, registration, examination and counseling) that ranged from half an hour to one hour and half, the majority $(21.0 \%, 65.7 \%)$ of them where either moderately or highly satisfied with such time. Similarly, a previously mentioned study by Kaoje et al (2015) reported that even though waiting time ranged from 30 min to two hours, the offered FP services were satisfied for utmost of the clients. A contradictory figure was shown by two previously mentioned studies by Wakjira (2017) and Argago et al (2015) who portrayed that clients were mainly unsatisfied with longer waiting time (>30 minutes). This contradiction may be related to the poor socioeconomic status of the studied FP clients in the present study coupled with the affordable cost of FP services in the governmental primary health care facilities compared to private ones which reinforce the clients' acceptance of 
long waiting time. Furthermore, the majority of the studied FP clients also reported that they were also had to wait for long time in the private services beside they must take an appointment in advance for long time that can reach several months.

To sum up, although in the existing study none of the studied FP clinics had high overall quality of FP care level (structure \& process) where two thirds of them had low total quality of care level, the majority of the FP clients had both moderate and high satisfaction level with the total quality of care level. This figure is in line with a previously mentioned study by De Silva and Fonseka (2008) which also indicated that despite the lower quality level of FP services, most of clients stayed satisfied with the offered FP services.

Furthermore, the current study also portrayed that the majority of the FP clients reported that they would use the same FP clinic for follow up, come back to the same FP clinic if they need any FP services, and recommended it to their relatives. Similar findings were reported by two studies. First and second, a former listed study by Nasr and Hassan (2016) and Tumlinson et al (2015) who studied the quality of care and contraceptive use in urban Kenya. Both studies found that nearly all respondents stated that they would utilize the same FP clinic again and recommend it to others. Such higher satisfaction with the service despite the unsatisfactory quality of care level could be explained by; the widespread culture of "Satisfaction with the little" among clients and courtesy bias which embarrass the clients to report the negative aspects of the service. In addition to, the lack of clients' knowledge about the acceptable standard of quality FP services that could be attributed to their background socio-demographic characteristics where they were mainly rural residents $(67.7 \%)$, had basic and secondary education (57.0\%), and 62.7\% had insufficient income level and loan to survive.

The present study showed that overall clients' satisfaction level with FP services was significantly and positively correlated with the total quality of care level, total structure and process attributes of quality. Concurred findings were revealed by four previously mentioned studies. First, Tessema et al (2017) showed that there was significant association between clients' satisfaction and quality of care level including both structure and process measures. Second, Kajoe et al (2015) revealed a significant correlation between clients' satisfaction and process quality. Third and fourth, Nasr and Hassan (2016) and Assaf et al (2015) portrayed that there was a statistically significant correlation between FP services structure quality and overall clients' satisfaction level. Thus, structural quality of FP clinics is a major contributing factor for clients' satisfaction. Facilities that possess good infrastructure and adequate equipment, supplies and FP methods while being accessible and cost effective can attract clients easily and motivate continuing service utilization. This portrayed that quality of care is not only based on the technical aspect of care but also on availability of good appealing facility that match clients' needs as a major contributing factor for clients' satisfaction with FP services.

\section{Conclusion}

The study findings revealed that none of the studied FP clinics had high total quality of care level where two thirds of them had low total quality of care level (structure \& process) which is insignificantly varied among the three studied FP clinics. In relation to structure quality, two thirds of the studied FP clinics had low total structure quality. Pertaining to process quality, none of the studied FP clinics had high total process quality where $66.6 \%$ of them had low total process quality. Regarding clients' satisfaction; 74.3\% of the studied FP clients were moderately satisfied with the overall FP services quality and almost equal percent $(13.0 \%, 12.7 \%)$ of them were either highly satisfied or unsatisfied. The majority $(73.7 \%, 22.3 \%)$ of the clients was moderately or highly satisfied with the total structure of FP services. However, $64.3 \%$ of them were moderately satisfied with the total process quality.

\section{Recommendations}

- The ministry of health should put primary health care centers especially FP clinics as a priority through setting up of service total quality development strategies.

- Implementation of in service training programs to improve staff technical competency about new trends of FP methods, standardized counseling, and clients' assessment and physical examination techniques.

- Establishing a system for continuous supervision and monitoring of FP clinics.

- Further researches should be carried out to:

- Assess the determinants factors of clients' satisfaction with FP services quality.

- Knowledge, practices, and attitudes of FP clients about FP methods.

\section{References}

Agha, S., \& Do, M. (2009). The quality of family planning services and client satisfaction in the public and 
private sectors in Kenya. International Journal of Quality Health Care, 21(2), 87-96. https://doi.org/10.1093/intqhe/mzp002

Agwanda, A., Khasakhala, A., \& Kimani, M. (2009). Assessment of Family Planning Services in Kenya: Evidence from the 2004 Kenya Service Provision Assessment Survey. Kenya Working Papers No. 4. Calverton, Maryland, USA: Macro International Inc. Retrieved July 15, 2009, from http://www.dhsprogram.com/pubs/pdf/WPK4/WPK4.pdf

Aiken, A.R.A., Dillaway, C., \& Mevs-Korff, N.A. (2015). Blessing I can't afford: factors underlying the paradox of happiness about unintended pregnancy. Social Science \& Medicine, 132(20), 149-155. https://doi.org/10.1016/j.socscimed.2015.03.038

Argago, T., Hajito, K., \& Kitilia, S. (2015). Clients' satisfaction with quality of family planning services and associated factors among family planning users in Hossana town public health facilities, South Ethiopia: facility-based cross-sectional study. International Journal of Nursing Midwifery, 7(5), 74-83. https://doi.org/10.5897/IJNM2015.0163

Assaf, S.H., Wang, W., \& Mallick, L. (2015). Quality of Care in Family Planning Services at Health Facilities in Senegal. DHS Analytical Studies No. 55. Rockville, Maryland, USA: ICF International. Retrieved July 14, 2017, from https://dhsprogram.com/pubs/pdf/AS55/AS55.pdf

Central Intelligence Agency (CIA). (2017). World Fact book. Egypt Demographics Profile. Retrieved October 4, 2017, from https://www.cia.gov/library/publications/the-world-factbook/

Cleland, J., Bernstein, S., Ezeh, A., Faundes, A., Glasier, A., \& Innis, J. (2006). Family planning: the unfinished agenda. WHO Sexual and Reproductive Health. The Lancet Sexual and Reproductive Health Series. Retrieved October 12, 2017, from http://www.thelancet.com/pdfs/journals/lancet/PIIS0140-6736(06)69480-4.pdf

De Silva, U., \& Fonseka, P. (2008). Quality of care in government family planning clinic services in Colombo District. Ceylon Medical Journal, 53(4), 121-127. https://doi.org/10.4038/cmj.v53i4.280

Dibaba, Y., Fantahun, M., \& Hindin, M.J. (2013). The effects of pregnancy intention on the use of antenatal care services: systematic review and meta-analysis. Reproductive health, 10(1), 50. https://doi.org/10.1186/1742-4755-10-50

Donabedian, A. (2005). Evaluating the Quality of Medical Care. Milbank Q, 83(4), 691-729. https://doi.org/10.1111/j.1468-0009.2005.00397.x

Donabedian, A., \& Ann. A. (1980). Mich Explorations in quality assessment and monitoring. The definition of quality and approaches to its assessment. Health Administration Press. Retrieved September 16, 2016, from https://www.amazon.com/Definition-Approaches-Assessment-Explorations-Monitoring/dp/0914904485

Hutchinson, P., Agha, S., \& Do, M. (2011). Measuring client satisfaction and the quality of family planning services: A comparative analysis of public and private health facilities in Tanzania, Kenya and Ghana. BMC Health Services Research, 11(203), 1-17. https://doi.org/10.1186/1472-6963-11-203

Hutchinson, P., Do, M., \& Agha, S. (2011). Client Satisfaction and the Quality of Family Planning Services: A Comparative Analysis of Public and Private Health Facilities in Ghana, Kenya, and Tanzania. BMC Health Services Research, 11(203), 1-17. https://doi.org/10.1186/1472-6963-11-203

Institute of Medicine. (2001). Committee on quality of health care in America. Crossing the quality chasm: a new health system for the 21st century. Washington, DC: National Academies of Science. Retrieved September 17, 2016, from http://www.nationalacademies.org/hmd/ /media/Files/Report\%20Files/2001/Crossing-the-Quality-Chasm/ Quality\%20Chasm\%202001\%20\%20report\%20brief.pdf

Institute of Medicine. (2010). In Ullmer, C.B.M. \& Burke, S (Eds.), Future directions for the national health care quality and disparities reports. Washington, DC: The National Academies Press. Retrieved December 20, 2016, from https://www.ahrq.gov/sites/default/files/wysiwyg/research/findings/final-reports/iomqrdrreport/iomqrdrrepo rt.pdf

Kaoje, U., Sambo1, N., Oche, O., Saad, A., Raji, O., \& Isah, A. (2015). Determinants of client satisfaction with family planning services in government health facilities in Sokoto, Northern Nigeria. Sahel Medical Journal, 18(1), 20-26. https://doi.org/10.4103/1118-8561.152154 
Metwally, A.M., Saleh, R.M., Abdelhamed, A.M., Salama, S.I., Mores, C.W., Shaaban, F.A., \& Azmy, O.M. (2015). Determinants of unintended pregnancy and its impact on the health of women in some governorates of Upper Egypt. J Arab Soc Med Res, 10, 1-8. https://doi.org/10.4103/1687-4293.159368

Ministry of Health and Population [Egypt], El-Zanaty and Associates [Egypt], and ICF International. Egypt (2015). Demographic and Health Survey 2014. Cairo, Egypt and Rockville, Maryland, USA: Ministry of Health and Population and ICF International. Retrieved August 15, 2017, from http://dhsprogram.com/pubs/pdf/fr302/fr302.pdf

Mohamed, S., Mohamed, A., \& Arief, A. (2017). Women Satisfaction with Family Planning Services in Maternal and Child Health Centers, Assiut City, Egypt. American Journal of Nursing Research, 5(3), 79-85. https://doi.org/10.12691/ajnr-5-3-2

Nasr, E., \& Hassan, H. (2016). Association between quality of family planning services and client's satisfaction level in maternal and child health centers in Port Said city. Journal of Nursing Education and Practice, 6(1), 85-99.

Rehman, F., Janjua, A.R., \& Shahzad, H. (2015). Client Satisfaction regarding Family Planning Services in Reproductive Center at Jinnah Hospital, Lahore. P J M H S., 9(3), 1048-1050.

Simbar, M., Ahmadi, M., Ahmadi, G., \& Majd, A. (2004). Quality assessment of family planning services in urban health centers of Shahid Beheshti Medical Science University. International Journal of Health Care Quality Assurance, 19(5), 430-442. https://doi.org/10.1108/09526860610680076

Tafese, F., Woldie, M., \& Megerssa, B. (2013). Quality of family planning services in primary health centers of Jimma zone, southwest Ethiopia. Ethiop J Health Sci., 23(3), 245-254. https://doi.org/10.4314/ejhs.v23i3.7

Tessema, G.A., Mahmood, M.A., Gomersall, JS., Assefa, Y., Zemedu, T.G., \& Kifle M. et al. (2017). Client and facility level determinants of quality of care in family planning services in Ethiopia: Multilevel modeling. PLOS ONE, 12(6), 1-20. https://doi.org/10.1371/journal.pone.0179167

Tumlinson, K. (2014). Measuring the quality of family planning service delivery in urban Kenya. Published dissertation. University of North Carolina. Retrieved February 10, 2017, from https://cdr.lib.unc.edu/indexablecontent/uuid

Tumlinson, K., Pence, B., Curtis, S., Marshall, S., \& Speizer, I. (2015). Quality of care and contraceptive use in urban Kenya. Int Perspect Sex Reprod Health, 41(2), 69-79. https://doi.org/10.1363/4106915

United Nations Department of Economic and Social Affairs, Population Division. (2017). Model-based Estimates and Projections of Family Planning Indicators. New York: United Nations. Retrieved August 11, 2017 , from http://www.un.org/en/development/desa/population/publications/pdf/family/Figure_Model-based_estimates _Countries_Run20170313.pdf

United Nations Population Fund (UNFPA). (2016). Universal Access to Reproductive Health: progress and challenges. $\quad$ Retrieved August $\quad 7, \quad$ 2017, from https://www.unfpa.org/sites/default/files/pubpdf/UNFPA_Reproductive_Paper_20160120_online.pdf

United Nations Population Information Network (POPIN). (1994). UN Population Division, Department of Economic and Social Affairs, with support from the UN Population Fund (UNFPA). International Conference on Population and Development (ICPD). Retrieved August 7, 2017, from http://www.un.org/popin/icpd/infokit/infokit.eng/lovervw.html

United Nations, Department of Economic and Social Affairs, Population Division. (2017). World population $\begin{array}{lllll}\text { prospects. } & \text { October } & \text { 4, } & \text { 2017, } & \text { from }\end{array}$ http://www.worldometers.info/world-population/egypt-population/

United states Department of Health and Human Services. (2014). Centers for Disease Control and Prevention. Providing Quality Family Planning Services: Recommendations of CDC and the U.S. Office of Population Affairs. Morbidity and Mortality Weekly Report. Recommendations and Reports. Retrieved August 7, 2016, from https://www.cdc.gov/mmwr/pdf/rr/rr6304.pdf

Wakjira, B.A. (2017). Assessment of Client Satisfaction on Family Planning Services Utilization in Wonji Hospital, Ethiopia 2016. JBR Journal of Clinical Diagnosis and Research, 5(1), 1-8. https://doi.org/10.4172/2376-0311.1000137

World Health Organization (WHO). (1978). Declaration of the Alma-Ata: International conference on primary 
health care. Alma-Ata, USSR: WHO. Retrieved Mach 22, 2017, from http://www.who.int/publications/almaata_declaration_en.pdf

World Health Organization (WHO). (2004). Department of reproductive health research (RHR). Improving the quality of family planning services delivery. Retrieved September 16, 2016, from http://www.who.int/reprodutivehealth/family_planningf/delivery.html

World Health Organization (WHO). (2004). Selected practice recommendations for contraceptive use (2nd ed.), Department of reproductive health and research. Family and Community Health. Geneva. Retrieved August 15, 2016, from http://www.who.int/reproductivehealth/ publications/family_planning/9241562846index/en/

World Health Organization. (2007). People-Centred Health Care: A policy framework. Regional office for the Western Pacific. Eighth meeting. Retrieved September 16, 2016, from http://www.wpro.who.int/health_services/people_at_the_centre_of_care/documents/ENG-PCIPolicyFrame work.pdf

Youssef, H., Osman, M., \& Roudi-Fahimi, F. (2014). Responding to rapid population growth in Egypt. Policy brief. Retrieved October 2, 2017, from http://www.prb.org/pdf14/egypt-rapid-population-growth.pdf

\section{Copyrights}

Copyright for this article is retained by the author(s), with first publication rights granted to the journal.

This is an open-access article distributed under the terms and conditions of the Creative Commons Attribution license (http://creativecommons.org/licenses/by/4.0/). 